This item was submitted to Loughborough's Research Repository by the author.

Items in Figshare are protected by copyright, with all rights reserved, unless otherwise indicated.

\title{
Do they know how hard I work? Investigating how implicit/explicit achievement orientation, reputation, and political skill affect occupational status
}

\section{PLEASE CITE THE PUBLISHED VERSION}

https://doi.org/10.1080/1359432X.2016.1225040

\section{PUBLISHER}

(C) Taylor \& Francis Group

\section{VERSION}

AM (Accepted Manuscript)

\section{PUBLISHER STATEMENT}

This work is made available according to the conditions of the Creative Commons Attribution-NonCommercialNoDerivatives 4.0 International (CC BY-NC-ND 4.0) licence. Full details of this licence are available at: https://creativecommons.org/licenses/by-nc-nd/4.0/

\section{LICENCE}

CC BY-NC-ND 4.0

\section{REPOSITORY RECORD}

Dietl, Erik, James A. Meurs, and Gerhard Blickle. 2016. "Do They Know How Hard I Work? Investigating How Implicit/explicit Achievement Orientation, Reputation, and Political Skill Affect Occupational Status". Loughborough University. https://hdl.handle.net/2134/35696. 
Do They Know how Hard I Work? Investigating how Implicit/ Explicit Achievement Orientation, Reputation, and Political Skill Affect Occupational Status

\author{
Erik Dietl \\ University of Hohenheim, Germany \\ James A. Meurs \\ University of Calgary, Canada
}

Gerhard Blickle

University of Bonn, Germany

Manuscript accepted for publication in European Journal of Work and Organizational Psychology - August 2016

(C) Taylor \& Francis Group. The manuscript may not exactly replicate the final version published in the journal. It is not the copy of record. The final article is available via its DOI: http://dx.doi.org/10.1080/1359432X.2016.1225040

Correspondence concerning this article should be directed to: Erik Dietl, Business and Organizational Psychology, University of Hohenheim, Wollgrasweg 49, 70599 Stuttgart, Germany, Email: erik.dietl@uni-hohenheim.de. 


\begin{abstract}
Researchers have yet to precisely test the Socioanalytic proposition that social skill moderates the personality identity - personality reputation relationship. Further, although research has found personality to have both explicit and implicit aspects, scholars have not examined these differences with respect to the Socioanalytic perspective on personality. The present study investigates how explicit and implicit achievement orientation identities relate to one's reputation for that trait in the workplace and to career success, as measured by occupational status. We propose that explicit and implicit achievement orientation, political skill, and their interplay positively relate to reputation of achievement orientation at work, which, in turn, is positively related to occupational status. We found that 1) both explicit and implicit achievement orientation were positively associated with its reputation, as rated by coworkers, 2) reputation mediated both relations between implicit/explicit achievement orientation and occupational status, and 3) heightened political skill strengthened the relationship between explicit achievement orientation and its reputation, as well as its indirect effect on occupational status via reputation (first stage moderated-mediation). Our research provides a potential explanation for why observer ratings of personality are more strongly associated with outcomes than self-ratings: Observers perceive both implicit and explicit personality behaviours.
\end{abstract}

Keywords: Socioanalytic theory, achievement orientation, implicit personality, personality reputation, political skill, occupational status 


\section{Do They Know how Hard I Work? Investigating how Implicit/ Explicit Achievement}

\section{Orientation, Reputation, and Political Skill Affect Occupational Status}

Socioanalytic theory argues that personality from the perspective of the self is an expression of a person's identity, whereas, other-observed personality reflects an individual's reputation (Hogan \& Shelton, 1998). In addition, social skill is thought to enhance one's ability to communicate personality to others, strengthening the personality identity personality reputation relationship (Hogan \& Shelton, 1998). However, prior research has not fully tested Socioanalytic theory, as previous studies (e.g., Blickle et al., 2008, 2011; Meurs, Perrewé, \& Ferris, 2011) did not include outcomes that directly measured personality reputation. There are many risks to using partially-tested theories, such as scholars prematurely trusting untested theoretical relationships and practitioners potentially being provided incorrect guidance. Thus, our study offers a test of this unexamined Socioanalytic proposition by assessing the personality identity - personality reputation relationship.

Personality identity contains both explicit and implicit elements (Back, Schmukle, \& Egloff, 2009; Brunstein \& Schmitt, 2004). Explicit personality involves controlled or conscious information processing and propositional reasoning, while implicit personality concerns automatic or nonconscious information processing and spontaneous behaviour. Most research relating personality to behaviour in organizations has relied on only explicit personality, despite the fact that both aspects of personality predict behaviour (Back et al., 2009). Additionally, scholars have expressed great interest in studies that examine how much variance overlap exists between implicit personality and personality reputation (Back et al., 2009). Our research not only examines implicit personality, but considers its incremental validity in predicting personality reputation beyond explicit personality.

We focus on the personality motive of achievement orientation, which has been shown to be a predictor of performance and career success (Dudley, Orvis, Lebiecki, \& 
Cortina, 2006; McClelland \& Franz, 1992), assessing the incremental validity of implicit achievement orientation, beyond an explicit measure, on achievement orientation reputation. Additionally, we test the Socioanalytic assertion that social skill at work moderates the relationship between explicit personality and personality reputation. Finally, informed by the Socioanalytic (Hogan \& Shelton, 1998) perspective, we argue that achievement orientation reputation will mediate the relationships that explicit and implicit achievement orientation have with career success, as measured via occupational status. Occupational status is an important work outcome, because it is related to societal perceptions of power, prestige, and authority afforded by the job (Schooler \& Schoenbach, 1994), as well as improved well-being (Rollero, Fedi, \& Piccoli, in press). The complete model of hypothesized relations is shown in Figure 1.

Our research makes three key contributions. First, our study augments the understanding of why observer ratings of a highly work-relevant personality trait (i.e., achievement orientation) are strongly predictive of important work-related outcomes (i.e., occupational status): personality reputation seems to be influenced by both the implicit and explicit personality of the target individual. Implicit personality may partly explain the predictive validity differences between explicit and observer-rated achievement orientation. This finding augments our knowledge of self- and other-accuracy (Connelly \& Ones, 2010). Second, although evidence suggests that achievement orientation operates at explicit and implicit levels (Brunstein \& Schmitt, 2004), organizational research has focused on explicit achievement orientation. Thus, our study answers the calls that research focus on alternatives to explicit measures (Morgeson, Campion, Dipboye, Hollenbeck, Murphy, \& Schmitt, 2007) and employ psychological theories of implicit self-concept to advance our understanding of important organizational phenomena (Chen, 2015). Third, by examining how a specific, work-related social skill (i.e., political skill; see Ferris, Harris, Russell, Blass, Ellen, \& 
Martinez, 2014) moderates the personality - reputation relationship and by focusing on the narrow personality characteristic of achievement orientation, we can account for previous contradictory findings (e.g., Blickle et al., 2008; 2013) regarding the relation between the broader but similar construct of conscientiousness and evaluations by others (e.g., job performance), as moderated by political skill.

\section{Theoretical Background and Hypothesis Development}

\section{Personality: A Socioanalytic Perspective}

Socioanalytic theory (Hogan \& Shelton, 1998) argues that, from within an individual, personality can be viewed as representing identities that are expressed in social interaction. People pursue goals in social settings, including those at work (Hogan \& Roberts, 2000). Thus, the behavioural expression of personality identity by an individual tells others how the person wants to be perceived, and, as such, could be considered self-presentations (Hogan \& Shelton, 1998). From outside of the individual, personality is reputation (Hogan \& Shelton, 1998), which is comprised of personality evaluations made by others that explain the actor's characteristic behaviour. Reputations are a valid method for forecasting future behaviour, because they are a summary of the target's past behaviour (Hogan \& Blickle, 2013). Reputations connect (i.e., mediate) the identity of an actor with how those motives are evaluated by others in the form of status and accomplishment (Hogan \& Shelton, 1998).

In our study, we describe achievement orientation, from the perspective of the self, as achievement orientation identity (Hogan \& Roberts, 2000). Personality identity has both explicit and implicit features (Back et al., 2009; Brunstein \& Schmitt, 2004). Explicit personality identity is built on a person's self-image and it refers to the values and desires people are able to articulate and report as being typical of their personality. Further, it is expressed in deliberate choice behaviour, such as a stated preference for difficult tasks 
(Brunstein \& Maier, 2005). Explicit personality is typically collected using self-reports of items with words that closely resemble the attribute concept (Pervin, 1994).

Conceptually, achievement orientation has been characterized as a general selfrepresentation of being successful, ambitious, and efficient in pursuing achievement-relevant goals (Brunstein \& Schmitt, 2004). Individuals high on explicit achievement orientation value superior performance and possess an intense motivation to reach the highest levels of skill and excellence. They strive to attain competence and success, embrace high standards, and seek goal accomplishment (Steers \& Braunstein, 1976).

Although the results for explicit achievement orientation are impressive (Dudley et al., 2006), there is evidence for concern about the validity of explicit personality. For instance, explicit self-reports are prone to both intentional and unintentional response distortion. In high-stakes testing and other evaluative situations, people purposefully manage the impression others have of them by presenting themselves more favourably in order to obtain valued rewards (Greenwald, Poehlman, Uhlmann, \& Banaji, 2009). For example, managers' explicit self-reports in 360-degree instruments have been found to be inflated and discrepant from observer ratings (Gentry, Hannum, Ekelund, \& De Jong, 2007). Second, explicit self-reports are conscious and reflective, allowing respondents to unintentionally distort their reports of socially desirable traits (Paulhus, 1984). Finally, the degree of accessibility to the self is limited via the explicit self-report method (Asendorpf, Banse, \& Mücke, 2002), because individuals struggle with accurately identifying the influences on their motivations (Wilson \& Brekke, 1994) and intuitions about oneself are difficult to consciously access (Wilson, Lindsey, \& Schooler, 2000). In personality assessment, all three of these tendencies can lower the validity of explicit self-reports. As achievement orientation, the focal personality construct of the present study, is highly desirable in work contexts, its explicit self-reports are likely prone to exaggeration, and research supports this contention 
(Birkeland, Manson, Kisamore, Brannick \& Smith, 2006). Thus, we believe achievement orientation is a construct that also should be assessed implicitly.

\section{Implicit Achievement Orientation}

As noted earlier, personality also has implicit aspects. Functional magnetic resonance imaging (fMRI) has shown that implicit associations are processed in the cortical areas of the brain related to automatic somatic and affective systems, while explicit cognitions are processed in regions associated with executive control and deliberation (Lieberman, 2007). These findings indicate the neurological independence of explicit and implicit processes, and psychological research on these implicit and explicit brain processes support fMRI results (see Strack \& Deutsch, 2004), uncovering automatic and intuitive motives, wishes, or desires that are not always directly accessible to self-perception, awareness, and consciousness (Back et al., 2009; Brunstein \& Schmitt, 2004; Kehr, 2004). Implicit motives tend to be triggered automatically by incentives intrinsic to performing an activity (e.g., mastering a challenging task triggers implicit achievement orientation) and, consequently, behaviour guided by these motivations contains little intentional thought by individuals (McClelland, Koestner, \& Weinberger, 1989). Thus, as has been supported by empirical results (e.g., Greenwald et al., 2009), implicit motives, such as implicit achievement orientation, are less open to the distortion found in explicit measures.

Situational cues stimulate these impulsive processes, which, over time and across situations, form associated personality motivations, characterized as implicit representations of the self (Back et al., 2009). Scholars have labelled implicit personality as self-concept, describing it as "an associative network containing all associations of the concept of self with attribute concepts describing one's personality" (Asendorpf et al., 2002; p. 381). Consequently, implicit personality could be characterized as an individual's more basic and enduring needs or motives, while explicit personality represent a person's self-consciously 
recognized characteristics (Brunstein \& Schmitt, 2004). Similar dual models (i.e., with implicit and explicit features) have been proposed in other psychological and social psychological fields, such as self-esteem (Greenwald \& Farnham, 2000), and social behaviour (Strack \& Deutsch, 2004).

Implicit achievement orientation is similar to its explicit counterpart, except that is a more affective, rather than cognitive, and a more internally-focused motive (Brunstein \& Maier, 2005). Implicit achievement orientation is one of the Big 3 implicit motives (Kehr, 2004). Given its nonconscious nature (Asendorpf et al., 2002), implicit personality predicts spontaneous behaviours (Back et al., 2009; Greenwald et al., 2009), and it needs to be indirectly measured, such as with an implicit association test (IAT; e.g., Brunstein \& Schmitt, 2004, for achievement orientation).

Consequently, we argue that coworkers perceive both implicit (spontaneous) and explicit (controlled) achievement oriented behaviours, forming the target's achievement orientation reputation. We believe that implicit achievement orientation will have a significant relationship with achievement orientation reputation, above and beyond that of explicit achievement orientation. Implicit achievement oriented behaviours that can be observed by coworkers are, for example, effortful performance or the energetic persistence in mastering challenging tasks using self-set standards. Whereas, explicit achievement behaviours typically comprise deliberate achievement-related task choices, or increased effort for short periods of time when other persons (e.g., supervisors) stress the importance of doing something well.

In support of this assertion, Brunstein and Schmitt (2004) demonstrated that implicit achievement orientation was independent from explicit achievement orientation and that each predicted different outcomes. Implicit achievement orientation uniquely predicted how hard students tried to improve their task performance, and explicit achievement orientation better 
predicted task enjoyment. Thus, implicit personality was associated with effort-related performance and explicit personality was linked to self-conscious evaluations, supporting arguments that implicit motives are related to primal motivation and explicit motives have a cognitive foundation (McClelland et al., 1989). Also, other IAT research has shown implicit associations to predict behaviour above and beyond that of explicit measures (e.g., Asendorpf et al., 2002; Back et al., 2009; see Greenwald et al., 2009 for a meta-analysis).

Theoretically, these results are in line with the behaviour regulation model by Back et al. (2009), which suggests that both reflective and impulsive processes influence behaviour. In addition, from a Socioanalytic perspective, whether triggered by automatic or reflective processes, behaviour has a strong impact on reputation (Hogan \& Shelton, 1998). Theoretical accounts and research findings suggest that implicit and explicit measures of similar individual characteristics each tap unique sources of variance and predict different classes of behavioural outcomes (Back et al., 2009; Brunstein \& Schmitt, 2004; Greenwald et al., 2009).

From the perspective of others, a target's personality constitutes personality reputation (Hogan \& Shelton, 1998). In relation to achievement orientation, we are not aware of studies relating explicit achievement orientation identity to achievement reputation, but research has examined the broader, related construct of conscientiousness. Conscientiousness can be characterized by the three main facets of orderliness, impulse control, and industriousness, which is closely related to achievement orientation (Roberts, Chernyshenko, Stark, \& Goldberg, 2005). Connelly and Ones (2010) found explicit conscientiousness to be moderately related to conscientiousness reputation among work colleagues. In addition, conscientiousness reputation is a better predictor of job performance than explicit self-reports (Connelly \& Hülsheger, 2012; Oh et al., 2011), yet it is unclear why. Connelly and Hülsheger (2012) argue that observers are able to more clearly perceive the targets than the targets 
perceive themselves, which, in turn, suggests that observers witness behaviours resulting from unrecognized (by the target) implicit personality identity. Consequently, we argue that implicit achievement orientation will have incremental validity in predicting achievement orientation reputation, beyond explicit achievement orientation.

Hypothesis 1. Implicit achievement orientation predicts achievement orientation reputation above and beyond explicit achievement orientation.

\section{Personality Identity, Personality Reputation, and Occupational Status}

Scholars have not only called for research examining the relationships between personality identity (i.e., explicit and implicit personality) and personality reputation (i.e., personality as observed by others), but also their prediction of outcomes (Back et al., 2009). Personality reputation has been argued to mediate the relationship that personality identity has with outcomes (Hogan \& Shelton, 1998). Accordingly, we contend that achievement orientation reputation mediates the relationships that implicit and explicit achievement orientation identity have with the outcome of occupational status.

Occupational status represents career success accumulated over time (Baruch \& Bozionelos, 2011), and, implicit motives are especially influential on long-term behavioural trends (McClelland \& Franz, 1992), such as those necessary to achieve status. Early studies linked implicit achievement orientation to career success (Cummin, 1967), including 10 yearlater work accomplishment (McClelland \& Franz, 1992). Meta-analytic research lends support to the long-term influence of implicit personality on behaviour (Spangler, 1992). Further, individuals make choices and achieve objectives to (eventually) reach long-term goals, and explicit personality particularly influences cognitive choices and goal setting (Ajzen, 1991; Locke \& Latham, 1990). Empirically, aspects of explicit achievement orientation have predicted several-decades-later occupational status (Judge \& Kammeyer- 
Mueller, 2012) and hierarchical status (Holtschlag, Morales, Masuda, \& Maydeu-Olivares, 2013). Clearly, achievement orientation is associated with workplace success and status. Concerning personality reputation's relationships with outcomes, Connelly and Ones' (2010) meta-analysis indicated that reputation predicted target behaviours related to both academic achievement and job performance. In regards to occupational status, it has been argued that those with a favourable reputation are viewed as more competent and often gain higher status (Tsui, 1984). One study found that reputation mediated the influence of individual differences on career success (Zinko, Ferris, Humphrey, Meyer, \& Aime, 2012), and it has been argued that personality identity is an antecedent of reputation and that career success is a consequence of reputation (Ferris et al., 2014; Hogan \& Shelton, 1998). We believe that targets having a higher reputation for achievement orientation (i.e., persons that are viewed as ambitious, efficient, competent, and successful) are more likely to gain a prestigious position with higher status, as groups use their perceptions of individuals' desired attributes to award higher and lower status (Anderson \& Cowan, 2014). Thus, we hypothesize:

Hypothesis 2. Achievement orientation reputation mediates the positive relationships that implicit and explicit achievement orientation have with occupational status. Further, the indirect effect of implicit achievement orientation on occupational status will be above and beyond the indirect effect of explicit achievement orientation.

\section{Socioanalytic Theory, Personality, and Political Skill}

Socioanalytic theorists argue that most people care deeply about their reputations, and that individuals are motivated to achieve their goals in social environments (Hogan \& Shelton, 1998). Therefore, people use social skill to more effectively communicate their personality identities to others and persuade them to agree with their self-presentations (Hogan \& Blickle, 2013). In other words, the link between explicit personality and 
personality reputation is moderated by social skill, and, as suggested by Hogan and Shelton (1998), the absence of social skill is likely to leave high (explicit) achievement orientation unfulfilled.

In the present study, we utilize political skill (Ferris et al., 2014) as a moderator of the personality identity - reputation relationship. Politically skilled individuals are adept at understanding and interpreting others and social situations, and they portray themselves and their desires in ways that influence coworkers (Ferris et al., 2005). We contend that political skill allows employees with high explicit achievement orientation to translate their achievement orientation identity into observable actions noticed by coworkers, leading to an increased achievement orientation reputation. Politically skilled employees "combine social astuteness with the capacity to adjust their behaviour to different and changing situational demands" (Ferris et al., 2005, p. 127) and are able to effectively influence others. Hence, employees high on both explicit achievement orientation and political skill should be able to advantageously use social situations to communicate their strivings to coworkers, such that their desires for excellence will be recognized by others.

We believe that political skill is the most relevant workplace social skill to strengthen effects of explicit achievement orientation on reputation, as political skill was the most valuable social skill among several constructs in previous research (i.e., political skill, selfmonitoring, self-efficacy, and emotional intelligence, Semadar, Robins, \& Ferris, 2006). In support of our arguments, prior Socioanalytic research showed political skill to interact with explicit personality in prediction of a target's work outcomes as evaluated by others (e.g., Blickle et al., 2008, 2011; Meurs et al., 2011). Finally, although only about a related construct, one study (Blickle et al., 2008) demonstrated that political skill moderates the (explicit) conscientiousness - job performance relationship, but another did not (Blickle et 
al., 2013). These mixed findings could be because the broad domain of conscientiousness lacks specificity (Paunonen, Rothstein, \& Jackson, 1999).

In relation to personality, researchers have called for the examination of potential moderators of explicit and implicit personality on outcomes (Back et al., 2009; Uhlmann, Leavitt, Menges, Koopman, Howe, \& Johnson, 2012). As the above discussion indicates, the cognitive and action tendencies related to explicit personality (Kehr, 2004) provide the foundation for political skill's influence on explicit, but not implicit, personality's relationship with reputation. Also, self-perceived social abilities (e.g., political skill) and explicit motives (e.g., explicit achievement orientation) must be combined to influence behaviour (Kehr, 2004). In sum, our study represents a more direct test than has been conducted by prior published research of the Socioanalytic contention that social skill (e.g., political skill) moderates the personality identity - personality reputation relationship.

For those high on explicit achievement orientation, we contend that high political skill will be related to improved achievement orientation reputation, because these individuals have strong achievement motives, and they know when and how to communicate their achievement identity to coworkers. On the other hand, without the ability to astutely read others at work, exercise influence, and communicate one's personality appropriately (i.e., low political skill), high explicit achievement orientation would be less noticed by coworkers.

Hypothesis 3. Political skill strengthens the positive relationship between explicit achievement orientation and achievement orientation reputation.

Personality, Political Skill, Reputation, and Status

Integrating the moderation (Hypothesis 3) of the relation between explicit achievement orientation and achievement orientation reputation with the mediation hypothesis (Hypothesis 2), we predict a first-stage moderated mediation model (Edwards \& Lambert, 2007; see Figure 1): 
Hypothesis 4 . There is a conditional indirect effect of explicit achievement orientation on occupational status, such that the mediated effect of explicit achievement orientation on occupational status through achievement orientation reputation is conditional on (i.e., moderated by) political skill. The indirect effect will be stronger among those high on political skill.

\section{Method}

\section{Participants and Procedure}

In order to obtain a sample that has sufficient variability in our variables of interest (i.e., achievement orientation), we recruited a diverse sample of German employees from a broad range of organizations and occupational backgrounds. Participants were personally approached and received upon agreement an e-mail including a link to an online questionnaire and a generated identification code. After providing self-reports, targets were asked to nominate, by reporting their e-mail-addresses, a maximum of six coworkers that could provide other-assessments of them at work. Then targets were forwarded to the implicit association test (IAT), assessing the implicit self-concept of achievement orientation (IATAOS). The IAT-AOS was administered online with the software Inquisit (2011).

Subsequently, we contacted nominated coworkers via e-mail to participate in the study. The e-mail to the coworkers contained general information about the survey, and a target identification-coded link to the coworkers' questionnaire. The target-identification codes allowed us to match the coworker questionnaires with the respective questionnaire of the target person. Of 302 targets contacted, 155 completed the online questionnaire (response rate $51.3 \%$ ). Of 514 coworkers contacted, 451 completed the peer rating questionnaire (response rate $87.7 \%$ ). Targets for which no coworker rating was available or no IAT measure could be obtained were removed from the sample. On average each target was rated by 2.63 coworkers, with 16 targets rated by 1 coworker, 33 targets by 2 coworkers, 68 targets 
by 3 coworkers, 6 targets by 4 coworkers, 4 targets by 5 coworkers and 1 target by 6 coworkers $(N=336$ other-raters $)$.

The final sample consisted of 128 target - coworker matched sets. $43.8 \%$ of the targets were female, and ages ranged from 18 to $66(M=41.91)$. Targets were employed in industries such as health care (17.2\%), civil service (14.8\%), social services provider $(10.2 \%)$, automotive (7.8\%), and telecommunication (3.9\%); and worked in functions such as marketing/ sales (15.6\%), research and development (7.0\%), occupational safety/ health protection $(6.3 \%)$, information technology $(6.3 \%)$, and accounting (4.7\%). On average, targets received more than 47,500 Euros annual salary, while working 38.62 hours per week $(S D=9.76)$. Coworkers worked with targets an average of 6.09 years $(\mathrm{SD}=5.28)$, met targets an average at least once per day $(\mathrm{M}=2.04, \mathrm{SD}=1.28$ on a scale from $1=$ several times a day to $6=$ at least once a month) and their work was medium to strongly interrelated with targets $(\mathrm{M}=2.73, \mathrm{SD}=1.03$ on a scale from $1=$ very strong to $5=$ not interrelated $)$. Measures

Achievement Orientation (Explicit / Self-report). Targets provided self-ratings for the 10 adjectives (i.e., ambitious, successful, efficient, curious, competent, idle, unsuccessful, inefficient, uninterested, and incompetent) from the Achievement Orientation Scale (AOS; Brunstein \& Schmitt, 2004), which showed convergent validity with Nygard and Gjesme's (1973) Achievement Motive Scale. All items were rated on a 5-point scale, ranging from $1=$ not at all true for me to $5=$ completely true for me. The internal consistency reliability of the Achievement Orientation Scale was $\alpha=.77$.

Achievement Orientation (Implicit / IAT Measure). The reliable and generally accepted tool for capturing implicit personality is the IAT developed by Greenwald, McGhee and Schwartz (1998). The IAT is robust to attempts at faking (Asendorpf et al., 2002), demonstrates acceptable internal consistency (Greenwald \& Farnham, 2000), and has test- 
retest reliability (Nosek, Greenwald \& Banaji, 2007). Moreover, it predicts behavioural outcomes across numerous areas of social behaviour (Greenwald et al., 2009).

Target subjects completed the Implicit Association Test on Achievement Orientation (IAT-AOS) adapted by Brunstein and Schmitt (2004). The IAT is a computer-based task that requires participants to rapidly sort target stimuli items by category using a computer keyboard. In the first block, participants were presented with item words referring to two target categories, $M e$ (I, me, myself, mine, own) and Others (they, them, their, theirs, those), and asked to categorize them correctly (i.e., press the " $\mathrm{x}$ " key when item words from the category $M e$ appear, and the "m" key when item words from the category Others appear). The second and fourth experimental blocks involved sorting achievement related words into two categories, Successful (ambitious, successful, efficient, curious, competent) and Not successful (idle, unsuccessful, inefficient, uninterested, incompetent), swapping the key to press for each category between blocks. The third and fifth blocks required participants to use a shared response. Specifically, in the third block, a word related to the $M e$ or to the Successful category required a " $\mathrm{x}$ " key press, whereas a word related to the Others or to the Not successful category required a "m" key press. In the fifth and final block, the pairing was reversed (i.e., Me or Not successful was associated with "x", and Others or Successful was paired with "m". Target (Me vs. Others) and attribute (Successful vs. Not successful) stimuli and task sequence of blocks for the IAT-AOS are depicted in Table 1.

Differences in average response latency for the combined critical blocks 3 and 5 constitute the IAT measure (e.g., if associating achievement related words with words referring to the self takes less reaction time than associating achievement related words with words referring to other people, it indicates greater implicit achievement orientation). We scored the IAT-AOS according to the improved scoring algorithm (so-called D1 measure) described by Greenwald, Nosek, and Banaji (2003); the D1 measure is quite similar to the 
well-known effect-size measure $d$ (Cohen, 1977) and its size can be interpreted accordingly. The D1 scoring algorithm reflects the mean reaction time difference between the two critical blocks 3 and 5 (initial combined task vs. reversed combined task) in individual effect size units. The higher the IAT effect - the strength of association between achievement-related adjectives and the self-concept - the higher is the estimated implicit achievement orientation. To estimate the internal consistency, we calculated the split-half reliability of the IAT ( $\alpha=$ .73).

Political Skill (Explicit / Self-report). Target employees assessed their political skill using the 18-item Political Skill Inventory (PSI, Ferris et al., 2005) on a seven-point (1: strongly disagree - 7: strongly agree) Likert scale $(\alpha=.87)$. Sample items include "I always seem to understand people well" and "I am able to communicate easily and effectively with others".

Achievement Orientation Reputation (Explicit / Other-report). Coworkers assessed targets' achievement orientation reputation with the same 10-item AOS (ambitious, successful, efficient, curious, competent, idle, unsuccessful, inefficient, uninterested, and incompetent). For the other-ratings, the 5-point scale was converted into the third person perspective. After calculating intra-class correlations (ICCs, McGraw \& Wong, 1996) for coworker ratings of achievement orientation, which was $\operatorname{ICC}(1, k)=.61$, we averaged the peer ratings. Internal consistency of AOS-other was good $(\alpha=.84)$.

Occupational Status (Explicit/Self-report). Occupational status reflects the amount of power, prestige, and authority that is ascribed by society to a particular profession (e.g., Schooler \& Schoenbach, 1994). We asked targets to assess their occupational status with a scale frequently used in sociology (e.g., Hartmann, 2002) that is very similar to the Occupational Scale of Hollingshead's index of social position (Miller \& Salkind, 2002). The scale has also been used in recent organizational studies (e.g., Blickle \& Schnitzler, 2010). It 
comprises 15 levels, the lowest being 1 (unskilled worker) and the highest being 15 (proprietor of a large business). The scores of occupational status were normally distributed $\left(\right.$ skewness $=.180, \mathrm{SE}$ of skewness $=.214, \mathrm{Z}_{\text {skewness }}=.84 ;$ kurtosis $=-.145, \mathrm{SE}$ of kurtosis $=$ $\left..425, Z_{\text {kurtosis }}=-.34\right)$; both $\mathrm{z}$-scores of skewness and kurtosis did not significantly deviate from zero (z < 1.96; Field, 2009); zero values represent normal distributions, skewness $> \pm 2$ and kurtosis $> \pm 7$ are indicative of non-normal distributions (Curran, West, \& Finch, 1996). We collected additional data to validate the measure of occupational status in a sample of working adults. This scale demonstrated positive relations between the respondents' scores and their salary $[r(172)=.34, p<.001]$, their hierarchical position within their company $[0 \%$ $=$ bottom, $100 \%=$ top $r(231)=.30, p<.001]$, the number of employees that they supervise $[r(224)=.23, p<.001]$, and number of hierarchical levels below them in their organization $[r(231)=.33, p<.001]$

Control variables. We controlled for targets' gender, age and job tenure in years, because they are associated with career success (Ng, Eby, Sorensen, \& Feldman, 2005). Moreover, previous research demonstrated that gender (Bowen, Swim, \& Jacobs, 2000) and age (Waldman \& Avolio, 1986) influence other ratings (performance ratings), and that years of job experience is related to achievement striving (Barling, Kelloway, \& Cheung, 1996). Data Analyses

To test our hypotheses we conducted structural equations modelling analyses with manifest variables and maximum likelihood estimation using Mplus 7.3 (Muthén \& Muthén, 2012). We followed the procedures recommended by Edwards and Lambert (2007). First, we examined main effect and mediation hypotheses (Hypothesis 1-2). Second, we examined the moderation and moderated mediation hypotheses and the expected conditional indirect effects (Hypothesis 3-4). We used the ordinary least squares regression method for estimating direct 
and (conditional) indirect effects and generated bias-corrected $95 \%$ confidence intervals for the direct, indirect, or conditional indirect effects using 10,000 bootstrap samples.

Becker, Atinc, Breaugh, Carlson, Edwards, and Spector (2016) cautioned that control variables may hamper the analyses by unnecessarily consuming degrees of freedom, potentially biasing findings related to the hypothesized variables. Therefore, we tested the hypotheses without control variables and with all control variables (Becker et al., 2016). Since taking into account the control variables did not significantly affect our results, we only report the results with control variables ${ }^{1}$.

\section{Results}

\section{Preliminary Analyses}

We conducted confirmatory factor analyses (CFAs) to assess the discriminant validity of our study measures. We constructed three to four item parcels as composite indicators for each construct to achieve an optimal ratio of sample size to number of estimated indicators (Kamdar \&Van Dyne, 2007; Sun \& Van Emmerik, 2015). In addition, we built a latent construct for occupational status by fixing the variance of the single indicator to 1.0 and the error variance to zero (Brown, 2015). Our hypothesized four-factor model (i.e., explicit achievement orientation, achievement orientation reputation, political skill, and occupational status) showed good fit to the observed covariance matrix $\left(\chi^{2}(32, \mathrm{~N}=128)=41.94, p=.003\right.$; $\left.\chi^{2} / d f=1.74, \mathrm{CFI}=.953, \mathrm{TLI}=.934, \mathrm{RMSEA}=.076, \mathrm{SRMR}=.058\right)$, with significant factor loadings for all items. The four-factor measurement model also yielded a significant improvement in chi-square over more parsimonious models in which we combined the following variables to load on a single factor: explicit achievement orientation and political skill $\left(\Delta \chi^{2}(3)=95.23, p<.001\right)$; explicit achievement orientation and achievement orientation

\footnotetext{
${ }^{1}$ All results without controls are available from the first author upon request.
} 
reputation $\left(\Delta \chi^{2}(3)=91.79, p<.001\right)$; explicit achievement orientation and occupational status $\left(\Delta \chi^{2}(3)=98.02, p<.001\right)$; political skill and achievement orientation reputation $\left(\Delta \chi^{2}(3)=232.13, p<.001\right)$; achievement orientation reputation and occupational status $\left(\Delta \chi^{2}(3)=201.09, p<.001\right)$.

Table 2 reports descriptive information and bivariate correlations of all variables. We found a positive mean for implicit achievement orientation (.43), which suggests a moderately high achievement orientation (i.e., interpreted similar to Cohen's $d=.5$; Cohen, 1977). Having both a relatively large standard deviation (.38) and the presence of several negative scores, implicit achievement orientation is clearly a wide-ranging individual difference among participants. As expected, the measures of explicit and implicit achievement orientation were statistically independent from each other $(r=.12, p=.17)$. The size of this correlation is consistent with the literature on IAT - explicit correlations for personality traits (average $\mathrm{r}=.166$ in $\mathrm{k}=21$ studies, Greenwald et al., 2009) and the nonsignificant IAT - explicit AOS correlation found by Brunstein and Schmitt (2004). Tests of Main Effects and Mediation Hypotheses

Explicit and implicit achievement orientation were positively related to achievement orientation reputation $(r=.30, p<.001$; and $r=.22, p=.01)$ respectively. As stated by Hypotheses 1 , implicit achievement orientation predicts achievement orientation reputation $(b$ $=.18, p=.03$, see Table 3, Model 2) above and beyond explicit achievement orientation. Thus, Hypothesis 1 was supported. To test the mediation hypotheses, we estimated both indirect effects in one model, using the two independent variables of explicit and implicit achievement orientation (i.e., using the regressions from Model 2 and Model 7 in Table 3). By doing so, we estimated the indirect effects that are unique to each predictor relative to the other predictor in the model (Hayes, 2013). Results were in line with the hypothesized mediational model (Hypothesis 2). Specifically, the indirect effect of explicit achievement 
orientation on occupational status via achievement orientation reputation was positive and the bootstrapped $95 \%$ confidence interval did not include zero (indirect effect $=.389$, boot $S E=$ $.200,95 \%$ CI[.010; .943]). Further, Hypothesis 2 predicted that implicit achievement orientation indirectly predicts occupational status through achievement orientation reputation, above and beyond the indirect effect of explicit achievement orientation. Consistent with this hypothesis, we found a significant indirect effect of implicit achievement orientation on occupational status through reputation (indirect effect $=.305$, boot $S E=.208,95 \% C I[.007$; $.857])^{2}$. The results support Hypothesis 2.

Tests of Moderation and Mediated Moderation Hypotheses

Hypothesis 3 postulated that political skill strengthens the positive relation between explicit achievement orientation and achievement orientation reputation. We found a significant interaction between explicit achievement orientation and political skill $(b=.28, p$ $=.03$ ) on achievement orientation reputation (see Table 3, Model 4). Plotting the interaction (Figure 2) shows that the positive relationship between explicit achievement orientation and achievement orientation reputation was stronger for targets with high levels of political skill. As expected, we found a significant positive slope for explicit achievement orientation at high levels of political skill $(+1 S D$; see Figure $2 ; b=.39, p<.001)$ and at the mean of political skill $(b=.22, p=.01)$. At low levels of political skill $(-1 S D)$, the slope of explicit achievement orientation was not significant $(b=.05, p=.66)$. In addition, we tested whether political skill strengthens the positive relationship between implicit achievement orientation

\footnotetext{
${ }^{2}$ We also tested both indirect effects without partialling out the shared variance of the two predictors (i.e., without controlling for the other predictor). We found the size of both indirect effects of explicit and implicit achievement orientation to be higher. Results are available from the first author upon request.
} 
and achievement orientation reputation (see Table 3, Model 5). As expected, the interaction term was non-significant $(b=.03, p=.82)$. This supports our argument that only explicit achievement orientation is moderated by political skill. Further, Hypothesis 4 posited that achievement orientation reputation mediates the interaction effect of explicit achievement orientation and political skill on occupational status. In support of this hypothesis, we found a significant indirect effect of this interaction on occupational status through achievement orientation reputation (indirect effect $=.383$, boot $S E=.206,95 \% C I[.080 ; .933]$ ). Next, we compared the conditional indirect effect of explicit achievement orientation at one standard deviation above the mean (indirect effect $=.678$, boot $S E=.309,95 \% C I[.196 ; 1.422]$ ), and at one standard deviation below the mean (indirect effect $=.087$, boot $S E=.269,95 \% C I[-$ $.485 ; .607])$ of political skill. Consistent with Hypothesis 4 , the results indicate that the indirect effect of explicit achievement orientation was significant for political skill at one standard deviation above the mean, and at the mean, but it was nonsignificant at one standard deviation below the mean.

All our hypothesized effects (Hypothesis 1 to 4) remain significant when analysed without control variables. Adopting a strict viewpoint, occupational status may be viewed as an ordinal categorical variable. Therefore, we performed additional moderated mediation analyses in which we treated occupational status as an ordinal outcome using Mplus 7.3. (Muthén \& Muthén, 2012). The pattern of results remained the same and supported our hypotheses. ${ }^{3}$

\section{Discussion}

\footnotetext{
${ }^{3}$ To save space, we do not present results for these analyses, but they are available from the first author upon request.
} 
We found a significant and positive relationship between both explicitly and implicitly measured achievement orientation and achievement orientation reputation, as assessed by coworkers. Thus, both explicit and implicit personality contributed to workplace reputation. Further, achievement orientation reputation mediated the relationships that implicit and explicit achievement orientation had with occupational status. In addition, political skill strengthened the relation between explicit achievement orientation and its reputation, as well as explicit achievement orientation's indirect effect on occupational status via reputation (first stage moderated-mediation).

\section{Theoretical Implications}

Although Socioanalytic theory has received much empirical confirmation in recent years (see Hogan \& Blickle, 2013; Blickle et al., 2011), one of its fundamental propositions has yet to receive strict empirical testing, namely, the moderation of the personality identity - reputation relationship by social skill (Hogan \& Shelton, 1998). The present research supports this basic tenant, contributing to Socioanalytic theory. Our moderation results demonstrated that the (explicitly) high achievement oriented employees had an increased achievement orientation reputation when they also were high on political skill. Moreover, achievement orientation reputation mediated the effect of this interaction on occupational status.

Further, Socioanalytic theory argues that reputation is an essential mediator of the personality - workplace outcome relationship (Hogan \& Blickle, 2013). The present study found that implicit personality had an impact on pertinent reputation when considered in isolation (see correlation in Table 2) and, incrementally, in direct comparison with explicit personality (see Model 2 in Table 3). Thus, our study contributes to explaining why implicit motives have an impact on workplace outcomes. Also, our findings provide an explanation for the moderate to strong validity of personality reputation for outcomes (see Connelly \& 
Ones, 2010; Oh et al., 2011). Specifically, when individuals make inferences about a target's personality, they might have a more complete picture than the target's explicit self-reports. Observers form a target's reputation by perceiving both a target's controlled, deliberate behaviour, which is related to explicit personality, and a target's spontaneous, habitual, and impulsive behaviour, which is related to implicit personality. This reasoning is in line with the Johari window's blind spots, which consist of aspects known to others but not to the self (Luft \& Ingham, 1955).

In addition, our study answers calls from scholars to examine whether otherperceptions are tapping into implicit aspects of personality (Back et al., 2009; Vazire, 2010). Our findings indicate that achievement orientation reputation - a trait high in observability and high in evaluativeness (i.e., the social desirability of having a particular trait) at work - is related to implicit and explicit achievement orientation. Therefore, our results add knowledge to the literature on self- and other-accuracy, such as the self-other knowledge asymmetry model (Vazire, 2010). Further, our study expands the model by Back et al. (2009), because it includes reputation, explicit, and implicit personality.

Moreover, our results add to the political skill literature by showing that political skill can improve how well an individual is able to translate explicit personality into other's perceptions of the same. We found that, when possessing high political skill, the employee who has a strong explicit achievement orientation is better capable of influencing others such that they also acknowledge that this individual strives to achieve. Further, political skill assists individuals to convert their personal achievement desires to heightened status, by enhancing the likelihood that others will identify this striving and reward it.

Lastly, context plays an important role in organizational behaviour (Johns, 2006). Prior research has shown that individuals with motives to achieve were most likely to obtain higher status if their achievement desires differentiated them from others in their culture 
(Holtschlag et al., 2013). Since Germany has a more egalitarian country culture (Schwartz, 2006), it is possible that the country context enhanced the opportunity for those high on achievement orientation to differentiate themselves. However, country contexts with a less egalitarian culture, such as the U.S.A., may attenuate this opportunity for people high on achievement orientation.

\section{Strengths and Limitations}

In addition to the contributions outlined above, our study has further strengths. We received response rates greater than 50\% for both our self- and peer-reports. Moreover, our sample included individuals from a range of occupations and organizations, improving our findings generalizability. Next, our method for assessing implicit personality is recommended by scholars (i.e., IAT; Uhlmann et al., 2012). Also, we collected data from three different sources: target employee surveys, coworker questionnaires, and target reaction time data, minimizing common method bias concerns (Podsakoff, Mackenzie, \& Podsakoff, 2012). Further, we assessed the same trait by different methods (i.e., explicit self-report and implicit association), with these measures showing discriminant validity, but converging on the trait reputation criterion (Campbell \& Fiske, 1959).

Regarding limitations, our data is cross-sectional, and longitudinal research could even more strongly speak to the influence of political skill on trait reputation, because individuals gain reputations over extended periods of time (Zinko et al., 2012). We also cannot exclude reverse causation. It is possible that higher occupational status leads others to give someone a greater reputation for achievement orientation by inferring a target's reputation from the person's occupational status (Ferris, Blass, Douglas, Kolodinsky, \& Treadway, 2003). However, achievement orientation at work is a trait high in observability, and several longitudinal studies support the path from individual achievement orientation to career success (Cummin, 1967; McClelland \& Franz, 1992) and from implicit and explicit 
personality to academic performance (e.g., conscientiousness; Vianello, Robusto \& Anselmi, 2010). Also, examining our sample seems to provide evidence against reverse causation: On average, coworkers worked for more than six years with the target persons, met the target persons at least once a day, and their work tasks were medium to strongly interrelated. Thus, in our sample, coworkers likely formed achievement orientation reputations based on observations of the target's behaviour at work.

\section{Future Research Directions}

Several avenues for future research are related to the present study. Although untested in this study, other individual differences could moderate the implicit/ explicit achievement orientation - reputation relationship. For instance, low self-monitors who also were low on explicit agreeableness or conscientiousness were found to engage in greater counterproductive work behaviours (Oh, Charlier, Mount, \& Berry, 2013). Perhaps the sincerity motives of those low on self-monitoring would strengthen the implicit achievement orientation - personality reputation relationship. In addition, coworker-ratings of employees' political skill could potentially moderate the implicit achievement orientation - reputation relationship.

Moreover, impulsivity (vs. controlledness) as a trait, may affect how well achievement orientation reputation is predicted by explicit or implicit measures (Back et al., 2009; Hofmann, Gschwendner, Friese, Wiers, \& Schmitt, 2008), such that the positive relation between explicit achievement orientation and outcomes is stronger for persons with low impulsivity. Furthermore, employees with high levels of self-awareness (i.e., those who are more aware of their implicit self-concept) may reveal a high consistency between their implicit and explicit achievement orientation (Hofmann, Gschwendner, \& Schmitt, 2005). Consequently, for these people implicit and explicit measures could similarly predict outcomes, without showing incremental validity. Lastly, perfectionism shares some 
similarities to achievement orientation (Hewitt \& Flett, 1991), and it seems likely that high socially prescribed perfectionism may moderate the positive relation between explicit achievement orientation and its reputation, because the expectations of high standards by others may trigger deliberate choices to invest increased effort at work. In sum, future research could examine these and other moderators of the implicit and explicit personality personality reputation relationship.

Also, since reputations develop over time, future studies could test the longitudinal development of personality reputation as influenced by political skill and personality identity. Finally, scholars could examine these same relationships using a measure of reputation that is socially constructed among coworkers (e.g., Zinko et al., 2012), as opposed to the one in the present study that requires more frequent contact with the target individual.

\section{Practical Implications}

The present findings suggest that implicit measures are potentially useful and might complement explicit measures in applied contexts. The application of implicit measures may mitigate problems of self-report measures which are prone to impression management and social desirability in high-stakes testing, because IATs are robust to attempts at faking (Asendorpf et al., 2002). Furthermore, organizations may implement IATs in 360-degree multi-rater instruments for managerial development and promotion. In particular, assessing implicit personality may help to explain the discrepancies between managers' self-reports and observer-ratings, and could help managers gain self-insight.

Moreover, given the relationship of achievement orientation reputation with occupational status, other-perceptions of an employee's personality would seem to be valuable to organizations looking to discern which employees should receive promotions or other rewards. Also, political skill strengthens the relation between explicit personality and work outcomes. Thus, in addition to widely utilized methods of performance prediction (e.g., 
general mental ability tests, assessment centers), organizations could benefit from measuring personality and political skill. Political skill training could be especially useful for organizations that aim to assist marginalized employees to become more influential in the workplace. Such political skill training might entail exercises to enhance an employee selfawareness, discussions of case studies, experiential exercises, and developmental simulations (Ferris, Anthony, Kolodinsky, Gilmore, \& Harvey, 2002).

\section{Conclusion}

The present study found that both implicit and explicit achievement orientation associated with occupational status through achievement orientation reputation. Additionally, in line with Socioanalytic personality theory, we found that individuals high on explicit achievement orientation had an enhanced reputation of achievement orientation when they also were high on political skill. 


\section{References}

Anderson, C., \& Cowan, J. (2014). Personality and status attainment: A micropolitics perspective. In Cheng, J. T., J. L. Tracy, \& C. Anderson (Eds.), The psychology of social status (pp. 99-117). New York, NY: Springer Science and Business Media.

Ajzen, I. (1991). The theory of planned behavior. Organizational Behavior and Human Decision Processes, 50, 179-211. doi: 10.1016/0749-5978(91)90020-T

Asendorpf, J. B., Banse, R., \& Mücke, D. (2002). Double dissociation between implicit and explicit personality self-concept: The case of shy behavior. Journal of Personality and Social Psychology, 83, 380-393. doi: 10.1037/0022-3514.83.2.380

Back, M. D., Schmukle, S. C., \& Egloff, B. (2009). Predicting actual behavior from the explicit and implicit self-concept of personality. Journal of Personality and Social Psychology, 97, 533-548. doi: 10.1037/a0016229

Barling, J., Kelloway, E. K., \& Cheung, D. (1996). Time management and achievement striving interact to predict car sales performance. Journal of Applied Psychology, 81, 821-826. doi: 10.1037/0021-9010.81.6.821

Baruch, Y., \& Bozionelos, N. (2011). Career issues. In S. Zedeck (Ed.), APA Handbook of Industrial and Organizational Psychology, (pp. 67-114). Washington, DC, USA: APA.

Becker, T. E., Atinc, G., Breaugh, J. A., Carlson, K. D., Edwards, J. R., \& Spector, P. E. (2016). Statistical control in correlational studies: 10 essential recommendations for organizational researchers. Journal of Organizational Behavior, 37,157-167. doi: 10.1002/job.2053.

Birkeland, S. A., Manson, T. M., Kisamore, J. L., Brannick, M. T., \& Smith, M. A. (2006). A meta-analytic investigation of job applicant faking on personality measures. International Journal of Selection and Assessment, 14, 317-335. doi: 10.1111/j.14682389.2006.00354.x 
Blickle, G., Fröhlich, J., Ehlert, S., Pirner, K., Dietl, E., Hanes T. J. \& Ferris, G. R. (2011). Socioanalytic theory and work behavior: Roles of work values and political skill in job performance and promotability assessment. Journal of Vocational Behavior, 78, 136-148. doi: 10.1016/j.jvb.2010.05.010

Blickle, G., Meurs, J.A., Wihler, A., Ewen, C., Plies, A., \& Günther, S. (2013). The interactive effects of conscientiousness, openness to experience, and political skill on job performance in complex jobs: The importance of context. Journal of Organizational Behavior, 34, 1145-1164. doi: 10.1002/job.1843

Blickle, G., Meurs, J. A., Zettler, I, Solga, J., Noethen, D., Kramer, J., \& Ferris, G. R. (2008). Personality, political skill, and job performance. Journal of Vocational Behavior, 72, 377-387. doi: 10.1016/j.jvb.2007.11.008

Blickle, G., \& Schnitzler, A. (2010). Is the political skill inventory fit for personnel selection? An experimental field study. International Journal of Selection and Assessment, 18, 155-165. doi: 10.1111/j.1468-2389.2010.00497.x

Bowen, C., Swim, J. K., \& Jacobs, R. R. (2000). Evaluating gender biases on actual job performance or real people: A meta-analysis. Journal of Applied Social Psychology, 33, 648-665. doi: 10.1111/j.1559-1816.2000.tb02432.x

Brown, T. A. (2015). Confirmatory factor analysis for applied research (2nd ed.). New York: Guilford Press.

Brunstein, J. C., \& Maier, G. W. (2005). Implicit and self-attributed motives to achieve: Two separate but interacting needs. Journal of Personality and Social Psychology, 89, 205222. doi: 10.1037/0022-3514.89.2.205

Brunstein, J. C., \& Schmitt, C. H. (2004). Assessing individual differences in achievement motivation with the Implicit Association Test. Journal of Research in Personality, 38, 536-555. doi: j.jrp.2004.01.003 
Campbell, D. T., \& Fiske, D. W. (1959). Convergent and discriminant validation by the multitrait-multimethod matrix. Psychological Bulletin, 52, 81-105. doi: $10.1037 / \mathrm{h} 0046016$

Chen, G. (2015) Editorial. Journal of Applied Psychology, 100, 1-4. doi: 10.1037/apl0000009 Cohen, J. (1977). Statistical power analysis for the behavioral sciences (Rev. ed.). New York: Academic Press.

Connelly, B. S., \& Hülsheger, U. R. (2012). A narrower scope or a clearer lens for personality? Examining sources of observers' advantages over self-reports for predicting performance. Journal of Personality, 80, 603-641. doi: 10.1111/j.14676494.2011.00744.x

Connelly, B. S., \& Ones, D. S. (2010). An other perspective on personality: Meta-analytic integration of observers' accuracy and predictive validity. Psychological Bulletin, 136, 1092-1122. doi: 10.1037/a0021212

Cummin, P. C. (1967). TAT correlates of executive performance. Journal of Applied Psychology, 51, 78-81. doi: 10.1037/h0024246

Curran, P. J., West, S. G., \& Finch, J. F. (1996). The robustness of test statistics to nonnormality and specification error in confirmatory factor analysis. Psychological Methods, 1, 16-29. doi: 10.1037/1082-989X.1.1.16

Dudley, N. M., Orvis, K. A., Lebiecki, J. E., \& Cortina, J. M. (2006). A meta-analytic investigation of conscientiousness in the prediction of job performance: Examining the intercorrelations and the incremental validity of narrow traits. Journal of Applied Psychology, 91, 40-57. doi: 10.1037/0021-9010.91.1.40

Edwards, J. R., \& Lambert, L. S. (2007). Methods for integrating moderation and mediation: A general analytical framework using moderated path analysis. Psychological Methods, 12, 1-22. doi: 10.1037/1082-989X.12.1.1 
Ferris, G. R., Anthony, W. P., Kolodinsky, R. W., Gilmore, D. C., \& Harvey, M. G. (2002). Development of political skill. In C. Wankel, \& R. DeFillippi (Eds.), Research in management education and development, Volume 1: Rethinking management education for the 21st century (pp. 3-25). Greenwich, CT: Information Age Publishing.

Ferris, G. R., Blass, F. R., Douglas, C., Kolodinsky, R. W., \& Treadway, D. C. (2003). Personal reputation in organizations. In J. Greenberg (Ed.), Organizational behavior: The state of the science (2nd ed., pp. 211-246). Mahwah, NJ: Lawrence Erlbaum.

Ferris, G. R., Harris, J. N., Russell, Z. A., Blass, R., Ellen, P., \& Martinez, A. D. (2014). The role of reputation in the organizational sciences: A multilevel review, construct assessment, and research directions. In J. J. Martocchio (Ed.), Research in personnel and human resources management, Vol. 32 (pp. 241-303). Oxford, UK: Elsevier.

Ferris, G. R., Treadway, D. C., Kolodinsky, R. W., Hochwarter, W. A., Kacmar, C. J., Douglas, C., \& Frink, D. D. (2005). Development and validation of the political skill inventory. Journal of Management, 31, 126-152. doi: 10.1177/0149206304271386

Field, A. P. (2009). Discovering statistics using SPSS: (and sex and drugs and rock ' $n$ ' roll) ( $3^{\text {rd }}$ edition). London: Sage.

Gentry, W. A., Hannum, K. M., Ekelund, B. Z., \& De Jong, A. (2007). A study of the discrepancy between self- and observer-ratings on managerial derailment characteristics of European managers. European Journal of Work and Organizational Psychology, 16, 295-325. doi: 10.1080/13594320701394188

Greenwald, A. G., \& Farnham, S. D. (2000). Using the Implicit Association Test to measure self-esteem and self-concept. Journal of Personality and Social Psychology, 79, 10221038. doi: 10.1037/0022-3514.79.6.1022 
Greenwald, A. G., McGhee, D., \& Schwartz, J. (1998). Measuring individual differences in implicit cognition: The Implicit Association Test. Journal of Personality and Social Psychology, 74, 1464-1480. doi: 10.1037/0022-3514.74.6.1464

Greenwald, A. G., Nosek, B. A., \& Banaji, M. R. (2003). Understanding and using the implicit association test: I. An improved scoring algorithm. Journal of Personality and Social Psychology, 85, 197-216. doi: 10.1037/0022-3514.85.2.197

Greenwald, A. G., Poehlman, T. A., Uhlmann, E., \& Banaji, M. R. (2009). Understanding and using the Implicit Association Test: III. Meta-analysis of predictive validity. Journal of Personality and Social Psychology, 97, 17-41. doi: 10.1037/a0015575

Hartmann, M. (2002). Der Mythos der Leistungseliten (The myth of the achievement elites. Top careers and social background in economy, politics, justice administration, and science). Frankfurt: Campus.

Hayes, A. F. (2013). Introduction to mediation, moderation, and conditional process analysis. New York: Guilford.

Hewitt, P. L., \& Flett, G. L. (1991). Perfectionism in the self and social context: Conceptualization, assessment, and association with psychopathology. Journal of Personality and Social Psychology, 60, 456-470. doi: 10.1037/0022-3514.60.3.456

Hofmann, W., Gschwendner, T., Friese, M., Wiers, R. W., \& Schmitt, M. (2008). Working memory capacity and self-regulatory behavior: Toward an individual differences perspective on behavior determination by automatic versus controlled processes. Journal of Personality and Social Psychology, 95, 962-977. doi: 10.1037/a0012705

Hofmann, W., Gschwendner, T., \& Schmitt, M. (2005). On implicit-explicit consistency: The moderating role of individual differences in awareness and adjustment. European Journal of Personality, 19, 25-49. doi: 10.1002/per.537 
Hogan, R., \& Blickle, G. (2013). Socioanalytic theory. In N. D. Christiansen \& R. P. Tett (Eds.), Handbook of Personality at Work (pp. 53-70). New York: Routledge.

Hogan, R., \& Roberts, B. W. (2000). A socioanalytic perspective on person/environment interaction. In W. B. Walsh, K. H. Craik, \& R. H. Price (Eds.), New directions in person-environment psychology (pp. 1-24). Hillsdale, NJ: Lawrence Erlbaum.

Hogan, R., \& Shelton, D. (1998). A socioanalytic perspective on job performance. Human Performance, 11, 129-144. doi: 10.1080/08959285.1998.9668028

Holtschlag, C., Morales, C. E., Masuda, A., \& Maydeu-Olivares, A. (2013). Complementary person - culture values fit and hierarchical career status. Journal of Vocational Behavior, 82, 144-153. doi: 10.1016/j.jvb.2012.11.004

Inquisit 3.0.6.0 [Computer software]. (2011). Seattle, WA: Millisecond Software.

Judge, T. A., \& Kammeyer-Mueller, J. D. (2012). On the value of aiming high: The causes and consequences of ambition. Journal of Applied Psychology, 97, 758-775. doi: $10.1037 / \mathrm{a} 0028084$

Johns, G. (2006). The essential impact of context on organizational behavior. Academy of Management Review, 31, 386-408. doi: 10.5465/AMR.2006.20208687

Kamdar, D., \& Van Dyne, L. (2007). The joint effects of personality and workplace social exchange relationships in predicting task performance and citizenship performance. Journal of Applied Psychology, 92, 1286-1298. doi: 10.1037/0021-9010.92.5.1286

Kehr, H. M. (2004). Integrating implicit motives, explicit motives, and perceived abilities: The compensatory model of work motivation and volition. Academy of Management Review, 29, 479-499. doi: 10.5465/AMR.2004.13670963

Lieberman, M. D. (2007). Social cognitive neuroscience: A review of core processes. Annual Review of Psychology, 58, 259-289. doi: 10.1146/annurev.psych.58.110405.085654 
Locke, E. A., \& Latham, G. P. (1990). A theory of goal setting and task performance. Englewood Cliffs, NJ: Prentice-Hall.

Luft, J., \& Ingham, H. (1955). The Johari Window: a graphic model of interpersonal awareness. Proceedings of the Western Training Laboratory in Group Development. Los Angeles: University of California, Los Angeles.

McClelland, D. C, \& Franz, C. E. (1992). Motivational and other sources of work accomplishment in mid-life: A longitudinal study. Journal of Personality, 60, 679-707. doi: 10.1111/j.1467-6494.1992.tb00270.x

McClelland, D. C., Koestner, R., \& Weinberger, J. (1989). How do self-attributed and implicit motives differ? Psychological Review, 96, 690-702. doi: 10.1037/0033295X.96.4.690

McGraw, K. O., \& Wong, S. P. (1996). Forming inferences about some intraclass correlation coefficients. Psychological Methods, 1, 30-46. doi: 10.1037/1082-989X.1.1.30

Meurs, J. A., Perrewé, P. L., \& Ferris, G. R. (2011). Political skill as moderator of the trait sincerity-task performance relationship: A socioanalytic, narrow trait perspective. Human Performance, 24, 119-134. doi: 10.1080/08959285.2011.554469

Miller, D. C., \& Salkind, N. J. (Eds.). (2002). Handbook of research design and social measurement. London, UK: Sage.

Morgeson, F. P., Campion, M. A., Dipboye, R. L., Hollenbeck, J. R., Murphy, K., \& Schmitt, N. (2007). Reconsidering the use of personality tests in personnel selection contexts. Personnel Psychology, 60, 683-729. doi: 10.1111/j.1744-6570.2007.00089.x

Muthén, L.K., \& Muthén, B.O. (1998-2012). Mplus User's Guide. Seventh Edition. Los Angeles, CA: Muthén \& Muthén. 
Ng, T. W. H., Eby, L., Sorensen, K. L., \& Feldman, D. C. (2005). Predictors of objective and subjective career success: A meta-analysis. Personnel Psychology, 58, 367-408. doi: 10.1111/j.1744-6570.2005.00515.x

Nosek, B., Greenwald, A. G., \& Banaji, M. (2007). The Implicit Association Test at age 7: A methodological and conceptual review. In J. Bargh (Ed.), Automatic Processes in Social Thinking and Behavior (pp. 265-292). Philadelphia, PA: Psychology Press.

Nygard, R., \& Gjesme, T. (1973). Assessment of achievement motives: Comments and suggestions. Scandinavian Journal of Educational Research, 17, 39-46. doi: $10.1080 / 0031383730170104$

Oh, I., Charlier, S. D., Mount, M. K. \& Berry, C. M. (2013). The two faces of high selfmonitors: Chameleonic moderating effects of self-monitoring on the relationships between personality traits and counterproductive work behaviors. Journal of Organizational Behavior. doi: 10.1002/job.1856.

Oh, I., Wang, G. \& Mount, M. K. (2011). Validity of observer ratings of the Five-Factor Model of personality traits: A meta-analysis. Journal of Applied Psychology, 96, 762773. doi: $10.1037 / \mathrm{a} 0021832$

Paulhus, D. L. (1984). Two-component models of socially desirable responding. Journal of Personality and Social Psychology, 46, 598-609. doi: 10.1037/0022-3514.46.3.598

Paunonen, S. V., Rothstein, M. G., \& Jackson, D. N. (1999). Narrow reasoning about the use of broad personality measures for personnel selection. Journal of Organizational Behavior, 20, 389-405. doi: 10.1002/(SICI)1099-1379(199905)20:3<389::AIDJOB917>3.0.CO;2-G

Pervin, L. A. (1994). A critical analysis of current trait theory. Psychological Inquiry, 5, 103113. doi: 10.1207/s15327965pli0502_1 
Podsakoff, P.M., MacKenzie, S.B., \& Podsakoff, N.P. (2012). Sources of method bias in social science research and recommendations on how to control it. Annual Review of Psychology, 65, 539-569. doi: 10.1146/annurev-psych-120710-100452

Roberts, B. W., Chernyshenko, O. S., Stark, S., \& Goldberg, L. R. (2005). The structure of conscientiousness: An empirical investigation based on seven major personality questionnaires. Personnel Psychology, 58, 103-139. doi:10.1111/j.17446570.2005.00301.x.

Rollero, C., Fedi, A., \& Piccoli, N. D. (in press). Gender or occupational status: What counts more for well-being at work? Social Indicators Research. doi: 10.1007/s11205-0151039-x.

Schooler, C., \& Schoenbach, C. (1994). Social class, occupational status, occupational selfdirection, and job income: A cross-national examination. Sociological Forum, 9, 431458. doi: 10.1007/BF01466317

Schwartz, S. H. (2006). A theory of cultural value orientations: Explication and applications. Comparative Sociology, 5, 137-182. doi: 10.1163/156913306778667357

Steers, R. M., \& Braunstein, D. N. (1976). A behaviorally-based measure of manifest needs in work settings. Journal of Vocational Behavior, 9, 251-266. doi: 10.1016/00018791(76)90083-X

Semadar, A., Robins, G., \& Ferris, G. R. (2006). Comparing the validity of multiple social effectiveness constructs in the prediction of managerial job performance. Journal of Organizational Behavior, 27, 443-461. doi: 10.1002/job.385

Spangler, W. D. (1992). Validity of questionnaire and TAT measures of need for achievement: Two meta-analyses. Psychological Bulletin, 112, 140-154. doi: 10.1037/0033-2909.112.1.140 
Strack, F., \& Deutsch, R. (2004). Reflective and impulsive determinants of social behavior. Personality and Social Psychology Review, 8, 220-247. doi: 10.1207/s15327957pspr0803_1

Sun, S. \& van Emmerik, H. (2015). Are proactive personalities always beneficial? Political skill as a moderator. Journal of Applied Psychology, 100, 966-975. doi: $10.1037 / \mathrm{a} 0037833$

Tsui, A. S. (1984). A role set analysis of managerial reputation. Organizational Behavior and Human Performance, 34, 64-96. doi: 10.1016/0030-5073(84)90037-0

Uhlmann, E. L., Leavitt, K., Menges, J. I., Koopman, J., Howe, M., \& Johnson, R. E. (2012). Getting explicit about the implicit: A taxonomy of implicit measures and guide for their use in organizational research. Organizational Research Methods, 15, 533-601. doi: $10.1177 / 1094428112442750$

Vianello, M., Robusto, E., \& Anselmi, P. (2010). Implicit conscientiousness predicts academic performance. Personality and Individual Differences, 48, 452-457. doi: 10.1016/j.paid.2009.11.019.

Waldman, D. A., \& Avolio, B. J. (1986). A meta-analysis of age differences in job performance. Journal of Applied Psychology, 71, 33-38. doi: 10.1037/00219010.71 .1 .33

Wilson, T. D., \& Brekke, N. (1994). Mental contamination and mental correction: Unwanted influences on judgments and evaluations. Psychological Bulletin, 116, 117-142. doi: 10.1037/0033-2909.116.1.117

Wilson, T. D., Lindsey, S., \& Schooler, T. Y. (2000). A model of dual attitudes. Psychological Review, 107, 101-126. doi: 10.1037/0033-295X.107.1.101 
Vazire, S. (2010). Who knows what about a person? The self-other knowledge asymmetry (SOKA) model. Journal of Personality and Social Psychology, 98, 281-300. doi: doi.org/10.1037/a0017908

Zinko, R., Ferris, G. R., Humphrey, S. E., Meyer, C.J., \& Aime, F. (2012). Personal reputation in organizations: Two-study constructive replication and extension of antecedents and consequences. Journal of Occupational and Organizational Psychology, 85, 156-180. doi: 10.1111/j.2044-8325.2010.02017.x 


\section{Table 1}

Implicit Association Test of Implicit Achievement Orientation: Task Sequence and Stimuli

\begin{tabular}{|c|c|c|c|c|c|}
\hline \multirow[b]{2}{*}{ Block } & \multirow[b]{2}{*}{$\begin{array}{l}\text { No. of } \\
\text { trials }\end{array}$} & \multirow[b]{2}{*}{ Task } & \multicolumn{2}{|c|}{ Response key assignment } & \multirow[b]{2}{*}{ Items } \\
\hline & & & Left key & Right Key & \\
\hline 1 & 20 & Attribute discrimination & $\mathrm{Me}$ & Others & I, me, myself, mine, own; they, them, their, theirs, those \\
\hline 2 & 20 & Target discrimination & Successful & Not successful & $\begin{array}{l}\text { Ambitious, successful, efficient, curious, competent } \\
\text { Idle, unsuccessful, inefficient, uninterested, incompetent }\end{array}$ \\
\hline 3 & 60 & Initial combined task & $\begin{array}{l}\text { Successful or } \\
\text { me }\end{array}$ & $\begin{array}{l}\text { Not successful } \\
\text { or others }\end{array}$ & $\begin{array}{l}\text { Ambitious, successful, efficient, curious, competent, I, me, myself, mine, own } \\
\text { Idle, unsuccessful, inefficient, uninterested, incompetent, they, them, their, theirs, those }\end{array}$ \\
\hline 4 & 20 & Reversed target discrimination & Not successful & Successful & $\begin{array}{l}\text { Idle, unsuccessful, inefficient, uninterested, incompetent } \\
\text { Ambitious, successful, efficient, curious, competent }\end{array}$ \\
\hline 5 & 60 & Reversed combined task & $\begin{array}{l}\text { Not successful } \\
\text { or me }\end{array}$ & $\begin{array}{l}\text { Successful or } \\
\text { others }\end{array}$ & $\begin{array}{l}\text { Idle, unsuccessful, inefficient, uninterested, incompetent, I, me, myself, mine, own } \\
\text { Ambitious, successful, efficient, curious, competent, they, them, their, theirs, those }\end{array}$ \\
\hline
\end{tabular}

Note. The original German stimuli can be obtained from the first author. 
Table 2

Means, Standard Deviations, Correlations and Reliabilities of the Study Variables

\begin{tabular}{|c|c|c|c|c|c|c|c|c|c|c|}
\hline & & $\mathrm{M}$ & SD & 1. & 2. & 3. & 4. & 5. & 6. & 7. \\
\hline 1. & Sex & 1.44 & .50 & - & & & & & & \\
\hline 2. & Age & 41.91 & 11.82 & .06 & - & & & & & \\
\hline 3. & Job tenure & 10.81 & 9.07 & -.10 & $.68 * *$ & - & & & & \\
\hline 4. & Explicit Achievement Orientation (EAO) & 3.90 & .40 & -.09 & $.22 *$ & .12 & $(.75)$ & & & \\
\hline 5. & Implicit Achievement Orientation (IAO) & .43 & .38 & .02 & .15 & .11 & .12 & $(.73)$ & & \\
\hline 6. & Political Skill (PS) & 5.18 & .61 & .06 & -.05 & -.05 & $.28 * *$ & -.01 & $(.87)$ & \\
\hline 7. & Achievement Orientation Reputation (AOR) & 4.13 & .38 & -.08 & .17 & -.01 & $.30 * *$ & $.22 *$ & .04 & $(.84)$ \\
\hline 8. & Occupational Status & 7.30 & 2.94 & $.24 * *$ & $.51 * *$ & $.29 * *$ & $.26 * *$ & .11 & .05 & $.31 * *$ \\
\hline
\end{tabular}

Note. $N=128$ targets (rated by 336 coworkers). EAO = Explicit Achievement Orientation. IAO = Implicit Achievement Orientation. PS = Political Skill AOR = Achievement Orientation Reputation. Sex: $1=$ female, 2 = male. IAO scores range from negative (association of the self with "not successful" or low achievement) to positive (association of the self with "successful" or high achievement); scores approaching zero show weak associations between the self and achievement.

$* p<.05$,

$* * p<.01$. 
Table 3

Hierarchical Regressions on Achievement Orientation Reputation and on Occupational Status

\begin{tabular}{|c|c|c|c|c|c|c|c|c|c|c|c|c|c|c|}
\hline & \multicolumn{10}{|c|}{ Achievement Orientation Reputation } & \multicolumn{4}{|c|}{ Occupational Status } \\
\hline & \multicolumn{2}{|c|}{ Model 1} & \multicolumn{2}{|c|}{ Model 2} & \multicolumn{2}{|c|}{ Model 3} & \multicolumn{2}{|c|}{ Model 4} & \multicolumn{2}{|c|}{ Model 5} & \multicolumn{2}{|c|}{ Model 6} & \multicolumn{2}{|c|}{ Model 7} \\
\hline \multicolumn{15}{|l|}{ Predictors } \\
\hline Sex & -.07 & $(.06)$ & -.08 & $(.06)$ & -.07 & $(.06)$ & -.09 & $(.06)$ & -.09 & $(.06)$ & $1.33 * *$ & $(.44)$ & $1.46^{* *}$ & $(.42)$ \\
\hline Age $^{a}$ & $.01 *$ & $(.01)$ & $.01 *$ & $(.01)$ & $.01 *$ & $(.01)$ & $.01 *$ & $(.01)$ & $.01 *$ & $(.01)$ & $.12 * *$ & $(.03)$ & $.11 * *$ & $(.03)$ \\
\hline Job tenure ${ }^{a}$ & $-.01 *$ & $(.01)$ & $-.01 *$ & $(.01)$ & $-.01 *$ & $(.01)$ & $-.01 *$ & $(.01)$ & $-.01 *$ & $(.01)$ & -.02 & $(.03)$ & .00 & $(.03)$ \\
\hline EAO & $.24^{* *}$ & $(.08)$ & $.22 * *$ & $(.08)$ & $.23^{* *}$ & $(.08)$ & $.22 * *$ & $(.08)$ & $.22 * *$ & $(.08)$ & $1.28 *$ & $(.55)$ & .89 & $(.55)$ \\
\hline IAO & & & $.18 *$ & $(.08)$ & $.18^{*}$ & $(.08)$ & $.17 *$ & $(.08)$ & $.17 *$ & $(.08)$ & .15 & $(.56)$ & -.15 & $(.56)$ \\
\hline PS & & & & & -.02 & $(.05)$ & -.01 & $(.05)$ & -.01 & $(.05)$ & & & & \\
\hline EAO $\times$ PS & & & & & & & $.28 *$ & $(.13)$ & $.28^{*}$ & $(.13)$ & & & & \\
\hline IAO x PS & & & & & & & & & .03 & $(.13)$ & & & & \\
\hline AOR & & & & & & & & & & & & & $1.74 * *$ & $(.59)$ \\
\hline$R^{2}$ & .13 & & .16 & & & & & & & & .34 & & .38 & \\
\hline$\Delta R^{2}$ & & & .0 & & & & & & & & & & .04 & \\
\hline
\end{tabular}

Note. $N=128$ targets (rated by 336 coworkers). EAO = Explicit Achievement Orientation. $\mathrm{IAO}=$ Implicit Achievement Orientation. $\mathrm{PS}=$ Political Skill. AOR = Achievement Orientation Reputation. Sex: 1 = female, 2 = male. Values are unstandardized regression coefficients; standard error estimates are in parentheses. All lower-order terms used in interactions were centered prior to analysis. ${ }^{\text {a }}$ Standard error estimate values of .004 or .005 were rounded up to .01 .

$* p<.05$;

$* * p<.01$. 
Figure 1

Theoretical Model of all Variables and their Measurement

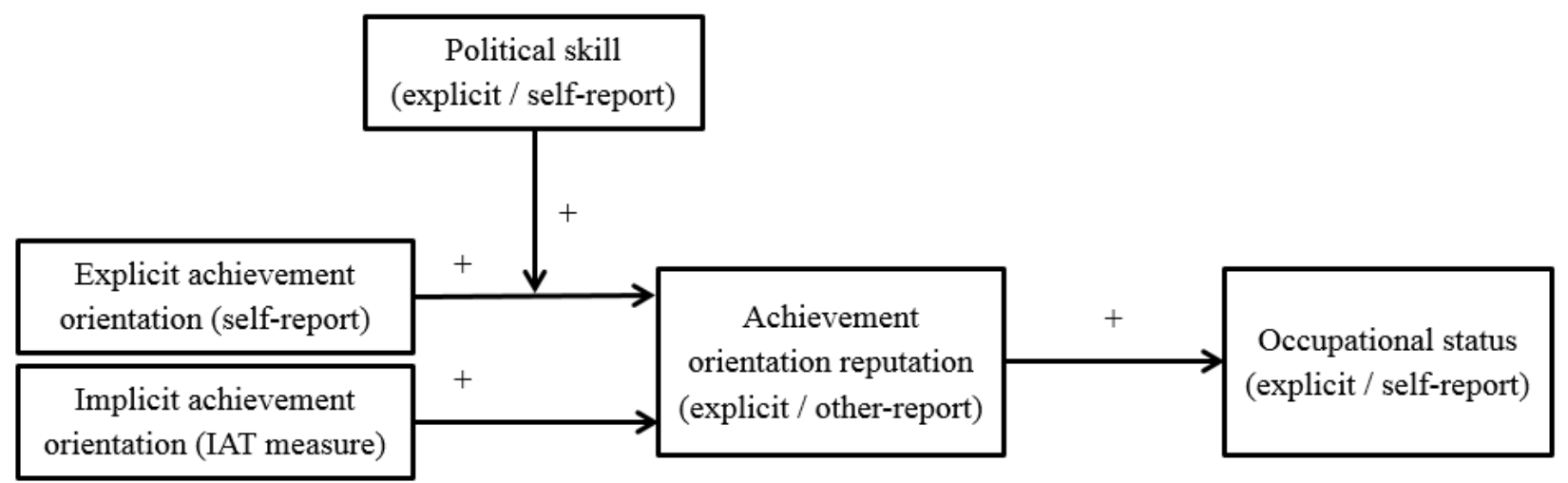


Figure 2

Achievement Orientation Reputation Regressed on Explicit Achievement Orientation and Moderated by Political Skill (Table 3, Model 4)

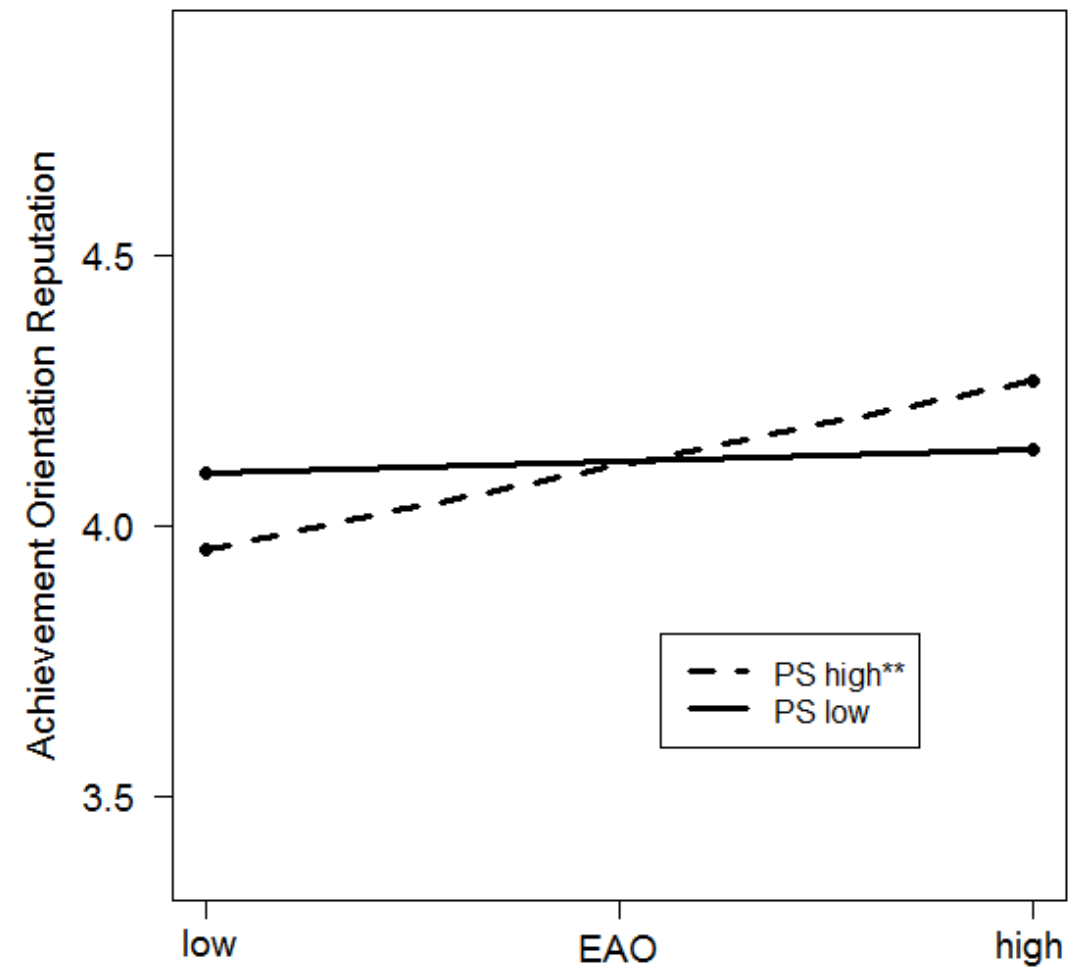

Note. $N=128$ targets (rated by 336 coworkers). EAO = Explicit Achievement Orientation; $\mathrm{PS}=$ Political Skill; the $\mathrm{y}$-axis is in the range of the mean $+/-2$ standard deviations. $* * p$ (slope $)<.01$. 